$\frac{51}{210.95}$ y5(2)

PREPARED FOR THE U.S. DEPARTMENT OF ENERGY, UNDER CONTRACT DE-AC02-76-CHO-3073

\section{PROGRESS IN COMPACT SOFT X-RAY LASERS} AND THEIR APPLICATIONS

PPPL-3031
BY

S. SUCKEWER AND C.H. SKINNER

JANUARY 1995

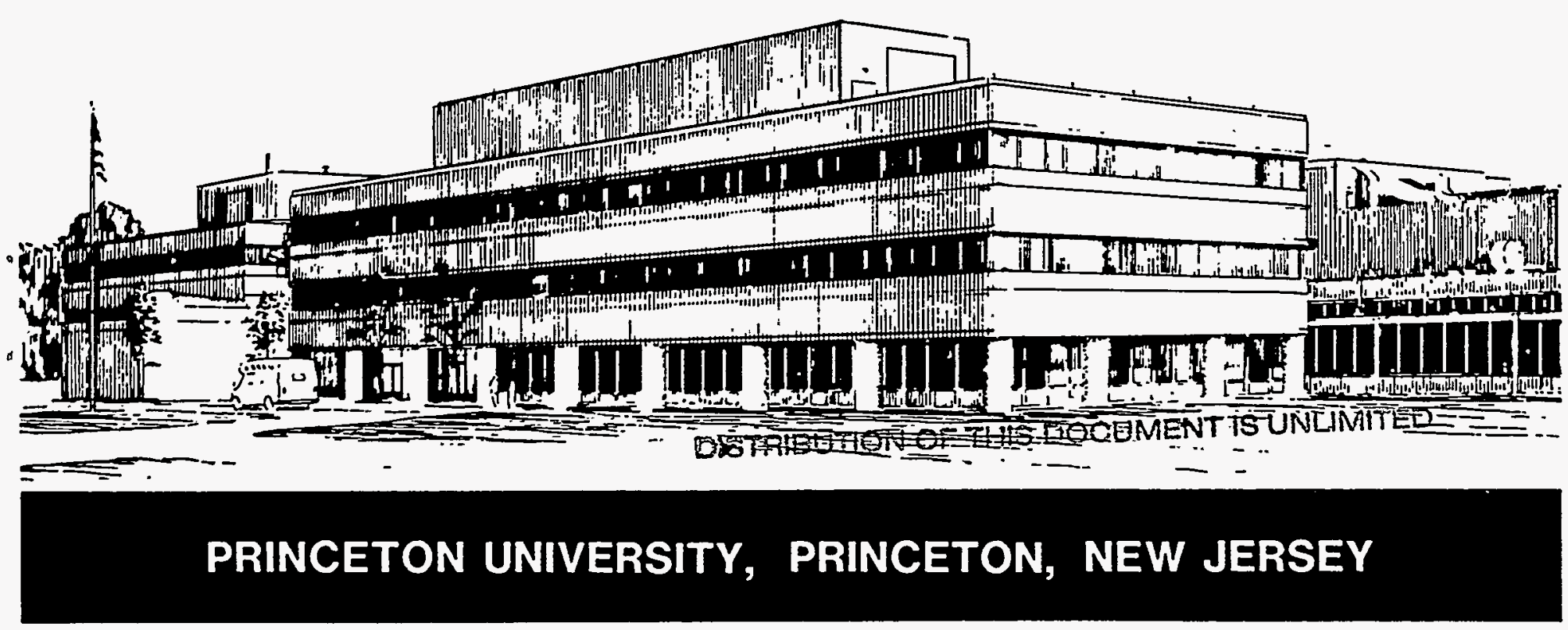




\section{NOTICE}

This report was prepared as an account of work sponsored by an agency of the United States Government. Neither the United States Government nor any agency thereof, nor any of their employees, makes any warranty, express or implied, or assumes any legal liability or responsibility for the accuracy, completeness, or usefulness of any information, apparatus, product, or process disclosed, or represents that its use would not infringe privately owned rights. Reference herein to any specific commercial produce, process, or service by trade name, trademark, manufacturer, or otherwise, does not necessarily constitute or imply its endorsement, recommendation, or favoring by the United States Government or any agency thereof. The views and opinions of authors expressed herein do not necessarily state or reflect those of the United States Government or any agency thereof.

\section{NOTICE}

This report has been reproduced from the best available copy. Available in paper copy and microfiche.

Number of pages in this report: 19

DOE and DOE contractors can obtain copies of this report from:

Office of Scientific and Technical Information

P.O. Box 62

Oak Ridge, TN 37831 ;

(615) 576-8401.

This report is publicly available from the:

National Technical Information Service

Department of Commerce

5285 Port Royal Road

Springfield, Virginia 22161

(703) $487-4650$ 


\section{DISCLAIMER}

Portions of this document may be illegible in electronic image products. Images are produced from the best available original document. 


\title{
Progress in Compact Soft X-ray Lasers*) and Their Applications
}

\author{
S. Suckewer and C. H. Skinner \\ Mechanical \& Aerospace Eng. Dept. and Plasma Physics Laboratory \\ P.O. Box 451 \\ Princeton University, Princeton. N.J. 08543
}

\begin{abstract}
The ultra-high brightness and short pulse duration of soft $\mathrm{x}$-ray lasers provide unique advantages for novel applications. A crucial factor in the availability of these devices is their scale and cost. Recent breakthroughs in this field has brought closer the advent of table-top devices, suitable for applications to fields such as x-ray microscopy, chemistry, material science, plasma diagnostics, and lithography. In this article we review recent progress in the development of compact (table-top) soft $\mathrm{x}$-ray lasers.
\end{abstract}

Keywords: soft $\mathrm{x}$-ray, laser, plasma, recombination.

\section{Introduction}

Exciting results announced at the recent 4th International Colloquium on X-ray Lasers brought the prospect of readily available compact (table-top) VUV and soft $\mathrm{x}$-ray lasers considerably closer. Lasing at $46.8 \mathrm{~nm}$ was observed in a capillary discharge, ${ }^{1}$ gain on the Lyman- $\alpha$ transition: $\mathrm{Li}$ III $13.5 \mathrm{~nm}$, induced by optical field ionization, ${ }^{2}$ was reported, and recombination table-top schemes pumped by low energy lasers showed continued progress. 3,4 The emerging technology of soft $\mathrm{x}$-ray lasers is in a transition phase between the first laboratory demonstrations of gain and the widespread acceptance of soft X-ray lasers (SXLs) as practical tools for novel applications. A key element here is the cost and availability of these devices and intensive efforts are being made to develop soft $\mathrm{x}$-ray lasers that will conveniently fit on a table top and be suitable for applications in the laboratories of researchers in academy and industry. These recent results augur well for the availability of table-top VUV and soft x-ray lasers in the near future.

We began work on application and miniaturization of SXL shortly after the demonstration of lasing action in 1984 at $18.2 \mathrm{~nm}$ in hydrogen-like carbon ions (CVI 3-2 transition). ${ }^{5}$ In this work

*)Invited paper for Comments on Atomic and Molecular Physics 
the gain medium was a rapidly recombining plasma, created by a 300J $\mathrm{CO}_{2}$ laser pulse and confined in a 50-90 kG magnetic field. The soft X-ray laser output energy of $3 \mathrm{~mJ}$ was ample for the first applications of soft X-ray lasers to microscopy. ${ }^{6}$ The $\mathrm{CO}_{2}$ laser and magnet are housed in a classroom sized room and has a repetition time of 3 minutes - nontheless it was not what we would call a compact or table top system. To be useful in the widest range of applications, miniaturization to a table-top system is desirable.

To produce gain and lasing action in a soft $\mathrm{x}$-ray laser a highly non-equilibrium condition is required in which an upper excited level in an plasma ion has a higher population than a lower level - this 'population inversion' is necessary to amplify light by stimulated emission. In our approach to compact soft X-ray lasers we choose to continue to work with a recombination scheme due to its high quantum efficiency (see Fig. 1). This was first proposed for the soft Xray wavelength region by Gudzenko et al ${ }^{7}$ and its principle is as follows: a plasma is generated by a conventional laser pulse focused onto a solid target or by an electrical discharge. Electron collisions in the hot $(>100 \mathrm{eV})$ plasma ionize the atoms until most are totally stripped of electrons. After the "pumping" pulse the plasma is rapidly cooled by adiabatic expansion, radiation cooling and/or thermal conduction to a low temperature $(\approx 10 \mathrm{eV})$ leading to rapid recombination. The plasma density is high so recombination occurs through a three body process in which an ion and two electrons collide. Recombination occurs preferentially to highly excited levels in hydrogen-like ions which cascade through collisions and radiative processes to the ground state. The upper state populations depend on the recombination rate which strongly increases at low temperatures - hence rapid cooling is essential to generating gain. The first excited state $(n=2)$ is depopulated particularly rapidly through Lyman $-\alpha$ radiation and a population inversion and gain builds up between levels $m=3$ and $n=2$. An analogous process occurs when helium-like ions recombine leading to population inversion and gain on transitions between the $4 \mathrm{f}, 5 \mathrm{~g}$ levels and the $3 \mathrm{~d}$ levels in lithium-like ions. ${ }^{8}$

An alternative approach to creating a population inversion is to exploit differences in collisional excitation rates to selectively populate a specific upper level in an ion - this is know as the collisional scheme. The lower level of the lasing transition is strongly depopulated by radiation (as in the recombination scheme) creating a population inversion. Recently P. Hagelstein and his group at MIT has shown that gain can be generated by the collisional scheme with low laser beam energy. ${ }^{3}$ The collisional approach was also used in the exciting demonstration of high gain in a capillary discharge ${ }^{1}$ (see later). Both of these systems are being developed as table top soft X-ray lasers. 
Mirrors are an essential part of conventional lasers, permitting multiple passes through the gain medium to build up intensity and create well defined laser beams. In the soft $\mathrm{x}$-ray range however, materials are only weakly reflective. Fortunately rapid progress in the development of layered synthetic microstructure mirrors has produced soft $\mathrm{x}$-ray reflectivities in excess of 50\% and enabled two-pass and cavity experiments.5,9-11 The mirror separation in a cavity must be short due to the limited gain duration but not too short otherwise the mirrors may be damaged by debris from the plasma. ${ }^{12,13}$ To date most experiments have demonstrated lasing action in a single pass.

\section{Compact Soft X-ray Laser Development}

\section{Recombination Scheme}

In this approach the large $\mathrm{CO}_{2}$ laser is replaced by a small-scale $\mathrm{Nd}$ laser which is brought to a line focus on a cylindrical carbon target. In the first experiments the plasma was confined in a magnetic field and high gain $\left(\mathrm{G} \approx 8 \mathrm{~cm}^{-1}\right)$ was measured for the CVI $18.2 \mathrm{~nm}$ line using a $15 \mathrm{~J}$, 3.5nsec Nd laser pulse. ${ }^{14}$ [Gain is defined in the usual way for amplifiers: output = input $\mathrm{x}$ $\exp (G L)$, where $G$ is the gain per unit length and $L$ is the length of the gain medium.] Later similar results were obtained without the magnetic field by surrounding the plasma with a miniature chamber with stainless steel walls and blades (see Fig. 2). ${ }^{15}$ This was a significant simplification as the $90 \mathrm{kG}$ magnet and associated capacitor bank could be dispensed with. In the new configuration the plasma initially expands rapidly allowing fast adiabatic cooling. After reaching the stainless steel walls and interacting with iron impurities from the laser ablation of the blades, the plasma is additionally cooled by thermal conduction to the walls and radiation losses from the iron ions. Medium $\mathrm{Z}$ ions such as iron have many strongly radiating transitions and the associated energy loss rapidly cools the plasma. In this way the optimum plasma conditions for high gain is created in the vicinity of the blades.

To further improve the gain we replaced the smooth carbon target with one consisting of many cooling "fins". The fins are $0.2 \mathrm{~mm}$ wide and separated by $0.06 \mathrm{~mm}$. The plasma created on the tip of each fin can initially expand in three dimensions and the faster expansion augments the adiabatic cooling and recombination rate. In Fig. 3 are shown the spectra in the vicinity of CVI $18.2 \mathrm{~nm}$ and $13.5 \mathrm{~nm}$ lines for 3 different target lengths: 2,4 and $6 \mathrm{~mm}$. The spectra were obtained from a plasma region between 0.3 and $0.5 \mathrm{~mm}$ from the target surface and for a separation of $0.8 \mathrm{~mm}$ between the cooling blades and the target surface. In the spectra one may see a strong increase of the intensity of both CVI lines with increasing plasma length. This increase in line intensities is faster than linear indicating high gain. A maximum gain of 
$7.1 \mathrm{~cm}-1$ for $18.2 \mathrm{~nm}$ line was generated with a remarkably low input laser energy of $4 \mathrm{~J}$ in a 2nsec pulse. 16 (The intensity of $13.5 \mathrm{~nm}$ line should be divided by 3 in order to take into account 3 times higher sensitivity of the spectrometer at $13.5 \mathrm{~nm}$ than at $18.2 \mathrm{~nm}$ ). In this figure we can see a linear increase of the CV $18.6 \mathrm{~nm}$ line intensity whereas the iron lines show a lower than linear intensity increase, which is an indication of significant opacity in these lines.

The observation of gain $\left(\mathrm{G}_{\max } \approx 6.5 \mathrm{~cm}^{-1}\right)$ on the 4-2 transition at $13.5 \mathrm{~nm}$ line was new for the multifin targets. In the smooth carbon targets the $13.5 \mathrm{~nm}$ line increased linearly with plasma length. Extensive checks showed that the measurements could not be attributed to target misalignment and the origin of gain on the $13.5 \mathrm{~nm}$ line is not well understood.

Control of the gain region in the plasma was demonstrated by changing the influx of iron into the plasma. 16 The amount of iron ablated from the blades into the plasma by the Nd laser is controlled by the distance between the cooling blades: with closer blades more iron ions are introduced in the active medium. The increase of the influx of iron shifts the gain region toward the target surface and allows us to reach higher gains. This demonstrates the importance of radiative cooling in the recombination soft X-ray laser schemes and illustrates the possibility of controlling the recombination process by varying of the iron influx into the plasma near the lasing region.

One might think that once gain has been demonstrated that the generation of high gain-lengths and useful output energies would be simply a matter of generating longer plasmas. However in many different compact recombination systems this has not been an easy task - typically the gain $/ \mathrm{cm}$ decreases as the plasma length increases, limiting the maximum gain-length achieved. One possible reason for this is refraction of the stimulated soft X-rays out of the gain region. The solution, as was demonstrated for the collisional scheme, 13 is to use multiple short targets pumped from opposite directions to guide the rays back to gain region. This approach should also work if there are other deleterious features of long plasma lengths. Currently we are using such a system of two relatively short $(6 \mathrm{~mm})$ targets pumped from opposite directions. We have further reduced the laser energy by shortening the laser pulse to $1.5 \mathrm{nsec}$ and optimal gain has been demonstrated for a single target with a $2.5 \mathrm{~J} \mathrm{Nd}$ laser pulse.

\section{Gain Generation by Optical Field Ionization}

Another avenue to the development of a compact SXL seems to be open by recent exciting results of Nagata et al (RIKEN). ${ }^{2}$ They used a low energy $(50 \mathrm{~mJ})$, high power subpicosecond $\mathrm{KrF}$ laser $\left(10^{17} \mathrm{~W} / \mathrm{cm}^{2}\right.$ in $\left.0.5 \mathrm{psec}\right)$ for optical-field-ionization (OFI) ${ }^{17}$ of the plasma column 
created by a second, very low power $(200 \mathrm{~mJ}$ in $20 \mathrm{nsec}) \mathrm{KrF}$ laser. [In OFI the plasma is ionized directly by the ultra intense electric field in the laser focus in contrast to the case at lower intensities where the plasma is ionized by electron collisions.] During the fast recombination of a $2 \mathrm{~mm}$ long plasma created by OFI they measured gain $\left(\mathrm{G} \approx 20 \mathrm{~cm}^{-1}\right)$ between the first excited level and the ground level (2- 1 transition) of $\mathrm{H}$-like LiII at $13.5 \mathrm{~nm}$. This is a very exciting result since the creation of a population inversion between an excited and ground level was previously considered to be extremely difficult as the ground state population is typically very high.

R. Falcone and his Berkeley/Livermore group 18 and our group 16 have attempted to repeat these results from RIKEN. Although in both experiments conditions were not exactly the same as those in RIKEN, nevertheless both groups obtained similar results. In the Berkeley/Livermore experiment a Ti: Sapphire subpicosecond laser was used at the fundamental $(\sim 0.8 \mu \mathrm{m})$ and at the second harmonic $(-0.4 \mu \mathrm{m})$. In our experiment which was only a slight modification of our earlier setup for a fast recombination plasma in a two-laser scheme ${ }^{19}$ we used a powerful $\mathrm{KrF}$ subpicosecond laser ( $\max$ power: $2 \times 10^{18} \mathrm{~W} / \mathrm{cm}^{2}$ in $0.3 \mathrm{psec}$ ) operating at power density $\approx 10^{17} \mathrm{~W} / \mathrm{cm}^{2}$, which is close to optimum for this experiment. We used a Nd/Glass laser for creating the initial plasma column from a LiF target. Although our spectra in the vicinity of the LiIII $13.5 \mathrm{~nm}$ line (Fig. 4) were quite similar to those of Nagata et al ${ }^{2}$ with maximum gain $\mathrm{G} \approx 17 \mathrm{~cm}^{-1}$ for a $2 \mathrm{~mm}$ long target, unfortunately we cannot yet make a definite statement about the measured gain in our case. This is due to the large line intensity fluctuations and difficulties to obtain a plasma column larger than $2 \mathrm{~mm}$ (probably caused by subpicosecond laser beam divegence). Hopefully applying a new method, ${ }^{20}$ recently developed for longer plasma generation with short laser pulses, it should be possible to obtain significantly larger gain-length and hence lasing action for such systems.

\section{Discharge Pumped Soft X-Ray and VUV Lasers}

An exciting breakthrough was reported recently in the generation of gain media for VUV lasers in a capillary discharge. ${ }^{1}$ Discharge pumping of soft $\mathrm{x}$-ray lasers has a strong advantage of technical simplicity and potentially much higher efficiency than laser drivers. High efficiencies are very advantageous because of the potential for associated cost and size reductions. In these experiments $200 \mu \mathrm{m}$ diameter plasma columns are generated by fast discharge excitation of capillary channels filled with preionized gas. ${ }^{21}$ The fast excitation pulse rapidly detaches the plasma from the capillary walls (as in a Z-pinch) enabling high plasma temperatures $\left(T_{e}>150 \mathrm{eV}\right)$ to be achieved. Initial work was aimed at generating gain in recombining plasmas where fast cooling was achieved by radiation and heat conduction to the capillary walls. However the most dramatic results were obtained very recently in collisionally excited neon-like $\operatorname{argon}^{1}$ (Fig. 5). 
Gain-lengths in excess of GL=7 at $46.8 \mathrm{~nm}$ were generated in capillaries of up to $12 \mathrm{~cm}$ length by pulses with a current risetime of $30 \mathrm{nsec}$. Initial estimates of the output energy were $0.1 \mathrm{~mJ}$ for only $50 \mathrm{~J}$ electrical energy input in the discharge. While this wavelength is in the VUV rather than the soft $\mathrm{x}$-ray region it is very suitable for applications in photochemistry for example. We expect that by changing discharge parameters (e.g. faster rise time) and medium (gas) it will be possible to obtain lasing action below $20 \mathrm{~nm}$ in near future.

Amplification at soft $\mathrm{x}$-ray wavelengths in a capillary discharge was also reported at two other institutions. At Pohang University, Pohang, Korea, soft $x$-ray gain was observed in a recombining plasma generated in a capillary discharge. ${ }^{22}$ Gain of $2.8 \mathrm{~cm}^{-1}$ was generated in a capillary $16 \mathrm{~mm}$ long on the $18.2 \mathrm{~nm}$ Balmer alpha transition in hydrogen-like CVI. At Ruhr Universität, Bochum, Germany, gain on the same transition was observed at the time of the second current maximum in the discharge. 23

It is clear that these exciting advances in several independent approaches to the development of affordable table-top VUV and soft x-ray lasers will soon turn the promise of such lasers into a reality.

\section{A New Method of Gain Measurement}

One of the experimental difficulties in systems in which the gain-length is low is that the stimulated emission intensity does not greatly exceed spontaneous levels. It can be difficult to identify the presence of gain and hence difficult to optimize the experimental conditions in order to increase it to more obvious levels. An additional difficulty in laser produced plasmas can be the presence of a high density region close to the target surface emitting intense spontaneous emission which obscures the stimulated emission from a gain region of lower density and limited spatial extent. A new method for detecting the presence of stimulated emission at low gainlengths down to $\mathrm{GL} \approx 0.1$ was proposed ${ }^{24}$ and implemented. ${ }^{4}$ The method is illustrated in Fig. 6 and is based on the major difference between stimulated and spontaneous emission, its directionality. An additional "probe" plasma is created some distance away from the "candidate" plasma by the same laser. On the opposite side of the candidate plasma is a multilayer mirror, reflective in the wavelength range of the gain line. The mirror provides spectral isolation of the gain line and reflects the light from both plasmas to the detector, a thinned back illuminated CCD (charge coupled device). A $1500 \AA \mathrm{Al}$ filter is used to reject visible light. When gain is present amplification of the emission from the probe plasma will be apparent in an enhanced intensity in the far field but only within the solid angle encompassing both the spontaneous 
emission region in the probe plasma and the gain region in the candidate plasma. A feature will appear in the far field pattern that can only be caused by directional, that is stimulated, emission.

By slightly modification of the experimental arrangement, an image of the plasma (e.g. in $18.2 \mathrm{~nm}$ light) can also be produced on the CCD using a simple pinhole. This is an extremely useful technique of aligning the two targets in two-plasma experiments and observing spatial characteristics of the plasma emission, for example, in the vicinity of the cooling blades. 4

\section{Example of Application: Soft X-Ray Reflection Microscopy}

$\mathrm{X}$-ray microscopy offers the opportunity of obtaining images of cells at resolutions much higher than available from light microscopy and free from possible artifacts due the intensive specimen preparation necessary in electron microscopy. The potential for $\mathrm{x}$-ray lasers to be used in biological imaging of living cells was recognized early on and the first images of cervical cancer cells obtained using a X-ray laser were reported in $1990 .^{6} \mathrm{X}$-ray microscopy has also been performed using soft $\mathrm{x}$-rays from synchrotrons and laser produced plasmas.

Besides conventional transmission $\mathrm{x}$-ray microscopy it is also possible to form an image from reflected $\mathrm{x}$-rays 25 with potential application to high resolution inspection of lithographic products and the observation of surfaces (or membranes) of biological cells. A proof-of-principle experiment at Princeton has demonstrated imaging of a test grid in reflected $\mathrm{x}$-rays from a soft $\mathrm{x}$ ray laser beam. 26 Such a SX reflection microscope with compact SXL as a source of SX radiation will be an attractive instrument. It will have important applications in materials sciences, for example in the characterization of semiconductor heterojunctions, for investigating buried interface structures, and the detection of precipitates inside silicon surfaces. The electronic properties of heterojunctions, namely metal-, semiconductor-, and insulatorsemiconductor interfaces, depends critically on the morphology of the interface. This morphology can be drastically affected by chemical reaction and interdiffusion that take place during interface formation or during subsequent processing steps. Thus a detailed characterization of the structure of these interfaces is extremely useful. Very few techniques are suitable for investigating buried interface structures. Most of them such as transmission electron microscopy, are destructive in the sense that the sample must be drastically modified, thinned down or cleaved. The reflection microscope will not require such sample preparation and the optimal wavelength range of 10-20 nm makes soft $\mathrm{x}$-ray laser the ideal source. It should be particularly powerful in the visualization of features and contrasted interfaces buried under overlayers $10-20 \mathrm{~nm}$ thick. A resolution of $50 \mathrm{~nm}$ is insufficient to provide an "atomic" picture 
but should provide valuable information on large scale inhomogeneities that exist at some interfaces.

\section{ACKNOWLEDGMENT}

We would like to express our appreciations to the whole X-ray laser group at Princeton University and particularly to A. Morozov and B. Fong for helping in the recent data analysis, and N. Tkach for technical support. We are grateful to R. Rocca (Colorado State University) for providing us with Fig. 5 prior to its publication. We would like to thank also C M Falco and J M Slaughter at the Optical Science Center at the University of Arizona for the multilayer mirrors. This work was supported by NSF and by the Office of Health and Environmental Research of DOE DE-AC02-76-CHO-3073.

\section{References}

1 J. J. Rocca, F. G. Tomasel, V. A. Shlyaptsev, D. O. Cortazar and G. Guidice, 4th International Colloquium on X-ray Lasers, Williamsburg, Va., May 16-20 (1994). (Proceedings in press).

2 Y. Nagata, K. Midorikawa, S. Kubodera, M. Obara, H. Tashiro and K Toyoda, Phys Rev. Lett. 71, 3774 (1993); K. Midorikawa et al., in Ref. 1.

3 P. Hagelstein, J. Goodberlet, M. Muendel, S. Basu, T. Savax, M. Fluery, and S. Kaushik, in Ref. 1.

4 A. Morozov, K. Krushelnick, L. Polonsky, C. H. Skinner and S. Suckewer, in Ref. 1.

5 S.Suckewer, C. H. Skinner, H. Milchberg, C. Keane, and D. Voorhees, Phys. Rev. Lett. $\underline{55}$, 1753 (1985); S. Suckewer, C. H. Skinner, D. Kim, E. Valeo and D. Voorhees, and A. Wouters, Phys. Rev.Lett. 57, 1004 (1986).

6 C. H.Skinner, D. S. DiCicco, D. Kim, R. J. Rosser, S. Suckewer, A. P. Gupta and J.G. Hirschberg, J. Micros. 159, 51-60, (1990).

7 L.I. Gudzenko and L. A. Shelepin, Sov. Phys. JEPT 18, 998 (1964); B. F. Gordiets, L.I. Gudzenko, and L. A. Shelepin, Sov. Phys. JEPT 2ㅇ, 489 (1969). 
9 N.M. Ceglio, D.G. Sterns, D.P. Gaines, A.M.Hawryluk, and J.E.Trebes, Opt. Lett.13, 108 (1988).

10 Y. Kato et al., in Ref. 1.

11 P. Jaeglé et al., in Ref. 1.

12 B. J. McGowan, et al., Proc. 3rd Int. Colloq. on X-Ray Lasers (Ed. E. Fill), Schliersee, Germany (1992), p. 269.

13 A.Carillon et al., Phys. Rev. Lett. 68, 2917 (1992).

14 D. Kim, C. H. Skinner, G. Umesh, and S. Suckewer, Optics Letters 14, 665 (1989).

15 C.H. Skinner, D. Kim, D. Voorhees, and S. Suckewer, J. Opt. Soc. Am. B 7, 2042 (1990).

16 L.Y. Polonsky, C.O. Park, K.Krushelnick, and S. Suckewer, Proc. SPIE Conference on Ultrashort Wavelength $\Pi$ (Ed. S.Suckewer), Vol. 2012, 75 (1993).

17 N. Burnett and P. B. Corkum, J. Opt. Soc. Am. B6, 1195 (1989); N. Burnett and G. D. Enright, IEEE J. Quant. Electr. 26, 1797 (1990); P. Amendt, D.C. Eder and S. C. Wilks, Phys.Rev. Lett. 66, 2589 (1991).

18 R. Falcone, Private communication (July 1993); T. Donnelly et al., in Ref. 1.

19 S. Suckewer, Proc. of the OSA on Short Wavelength Coherent Radiation: Generation and Applications (Falcone and Kirz eds.), Vol. 2, 28 (1988); W. Tighe, K. Krushelnick, E. Valeo and S.Suckewer, Proc. 2nd Int. Colloq. on X-Ray Lasers (Ed. G. Tallents), York, UK (1990), p. 317 .

20 C. G. Durfee, III and H.M. Milchberg, Phys. Rev.Lett. 1, 2409, (1993).

21 J. J. Rocca, D. C. Beethe and M. C Marconi, Optics Lett. 13, 565 (1988); J. J. Rocca, D. Cortazar, B. Szapiro, K. Floyd and F. G Tomasel, Phys. Rev. E 누, 1299 (1993).

22 T. N. Lee, H .J Shin and D. E Kim, in Ref. 1.

23 H. J . Kunze, K. N. Koshelev, S. Glenzer, C. Steden, D. Uskov, and H. T. Wieschebrink, in Ref. 1.

24 C.H. Skinner Optics Letters, 16, 1266-1268 (1991). 
23 H. J . Kunze, K. N. Koshelev, S. Glenzer, C. Steden, D. Uskov, and H. T. Wieschebrink, in Ref. 1.

24 C.H. Skinner Optics Letters, 16, 1266-1268 (1991).

25 S. Suckewer, C.H. Skinner, and R. Rosser, "Reflection Soft X-Ray Microscope", US Patent $\underline{5,177,774}$ (1993).

26 D. DiCicco, D. Kim, R. Rosser and S.Suckewer, Opt. Lett. 17. 157 (1992).

\section{Figure Captions:}

Fig. 1 Energy level diagram for H-like and Li-like ions showing the generation of gain in the recombination scheme.

Fig. 2 Experimental setup for the table-top soft x-ray laser. The plasma is surrounded by flexible steel walls to provide additional cooling. The $\mathrm{Ng}$ :glass laser beam enters through a stainless steel slot, $\approx 0.2 \mathrm{~mm}$ wide. Part of the upper blade and side wall has been cut away in the drawing to display the target.

Fig. 3 The spectra of the carbon target with 2,4 and $6 \mathrm{~mm}$ length. Laser energy is $4 \mathrm{~J}$ (for 12 $\mathrm{mm}$ line focus), slot distance from the target is $0.3 \mathrm{~mm}$, the distance between the target and the blades is $0.8 \mathrm{~mm}$.

Fig. 4 Spectra in vicinity of Li III $11.4 \mathrm{~nm}$ and $13.5 \mathrm{~nm}$ lines generated by the interaction of Powerful Subpicosecond (PSP) laser with $1 \mathrm{~mm}$ and $2 \mathrm{~mm}$ plasmas produced by a $\mathrm{Nd} / \mathrm{Glass}$ laser $100 \mathrm{nsec}$ earlier. Non-linear increase in intensity of the $13.5 \mathrm{~nm}$ line may indicate high gain.

Fig. 5 Variation of the intensity of the spectral lines in the neighborhood of $48 \mathrm{~nm}$ as a function of capillary length. For a $3 \mathrm{~cm}$ plasma column, the $46.8 \mathrm{~nm} \mathrm{~J}=0-1$ line of Ne-like $\mathrm{Ar}$ is observed to be less intense than the surrounding lines from $\mathrm{Mg}$-like and only about twice the intensity of the neighboring $48.5 \mathrm{~nm} 3 \mathrm{~d}-3 \mathrm{p}$ Ne-like Ar line. In the $6 \mathrm{~cm}$ capillary, the laser line is significantly more intense than its neighbors, while in the $12 \mathrm{~cm}$ plasma column the $\mathrm{J}=0-1$ line totally dominates the spectrum.

Fig. 6 Schematic showing the probe plasma, the candidate gain plasma and the far field detector. The expected far field emission pattern is shown with a feature due to the amplification in the candidate plasma of spontaneous emission from the probe plasma. 


\section{Recombination Scheme}

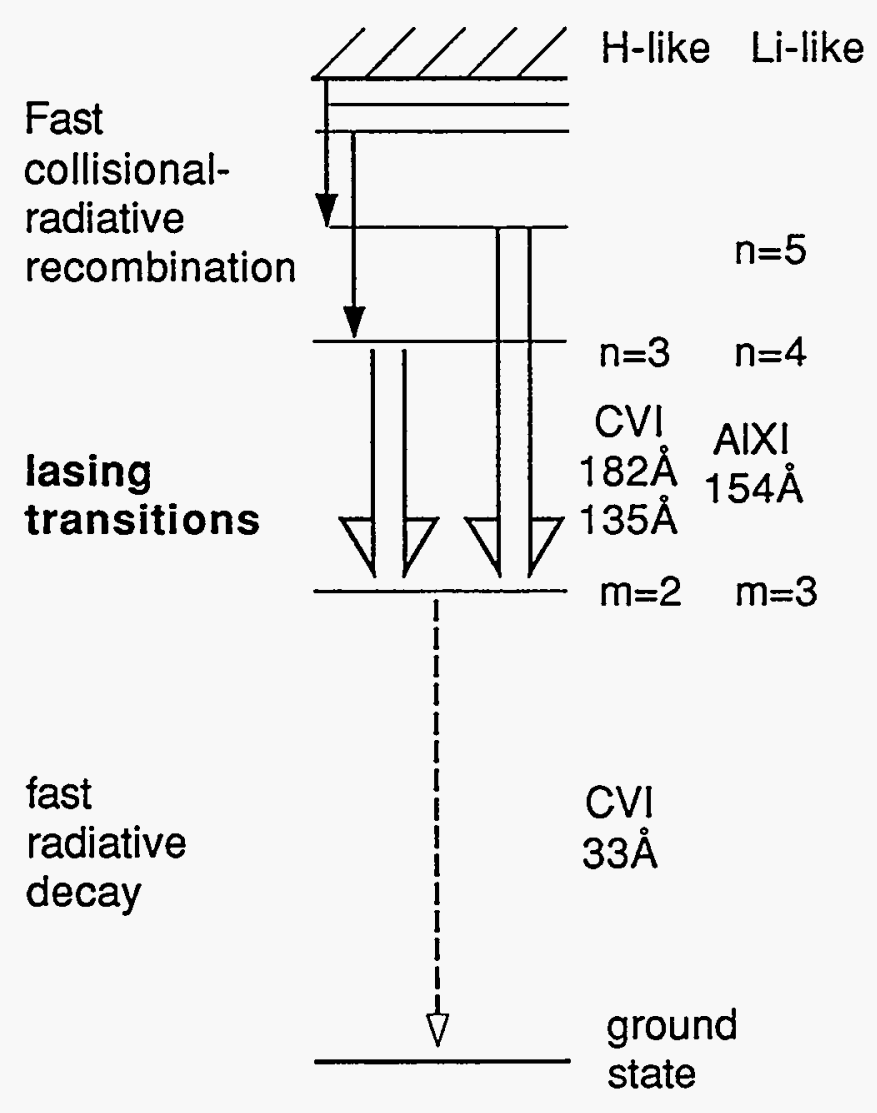

Fig. 1 

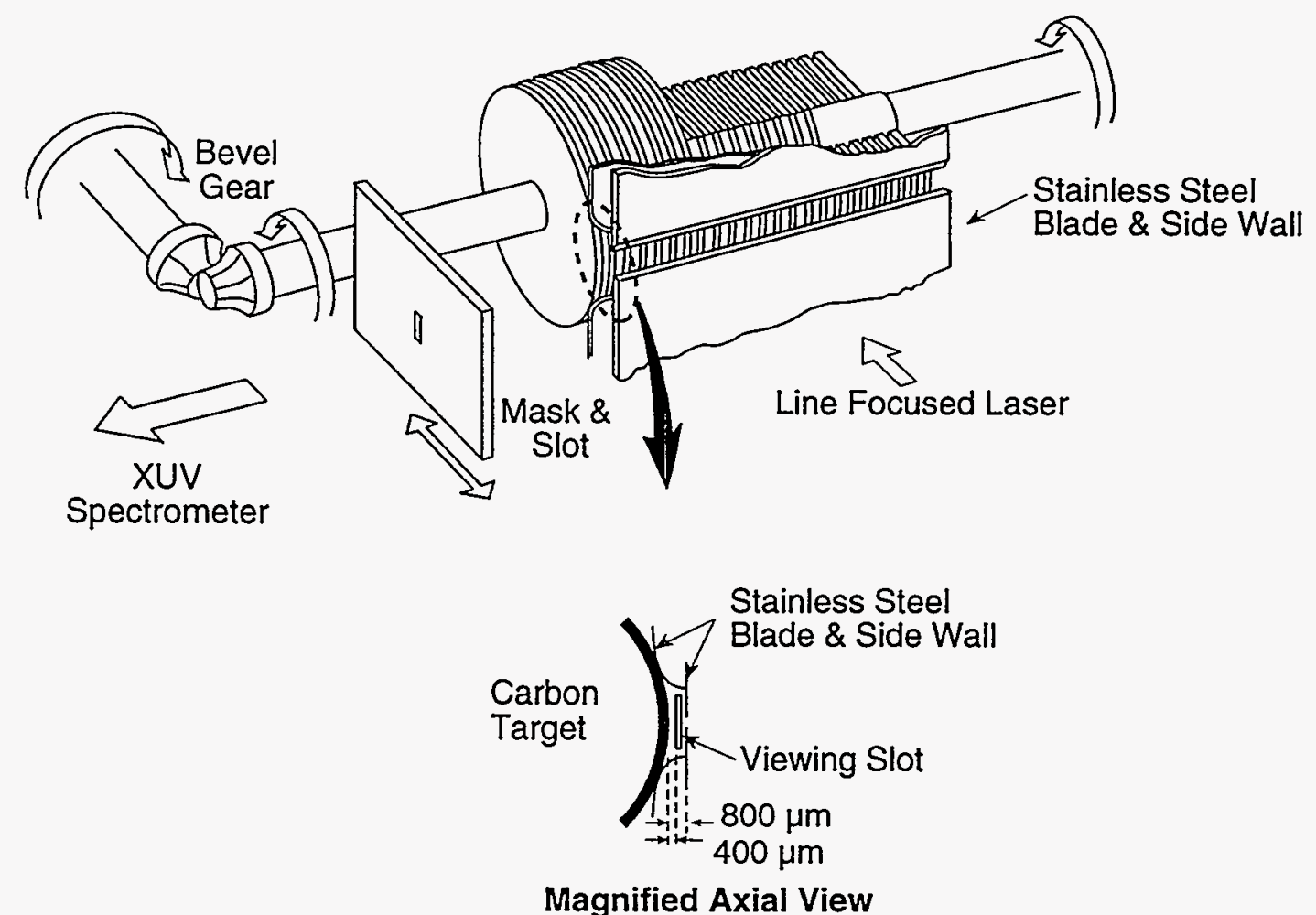

Fig. 2 

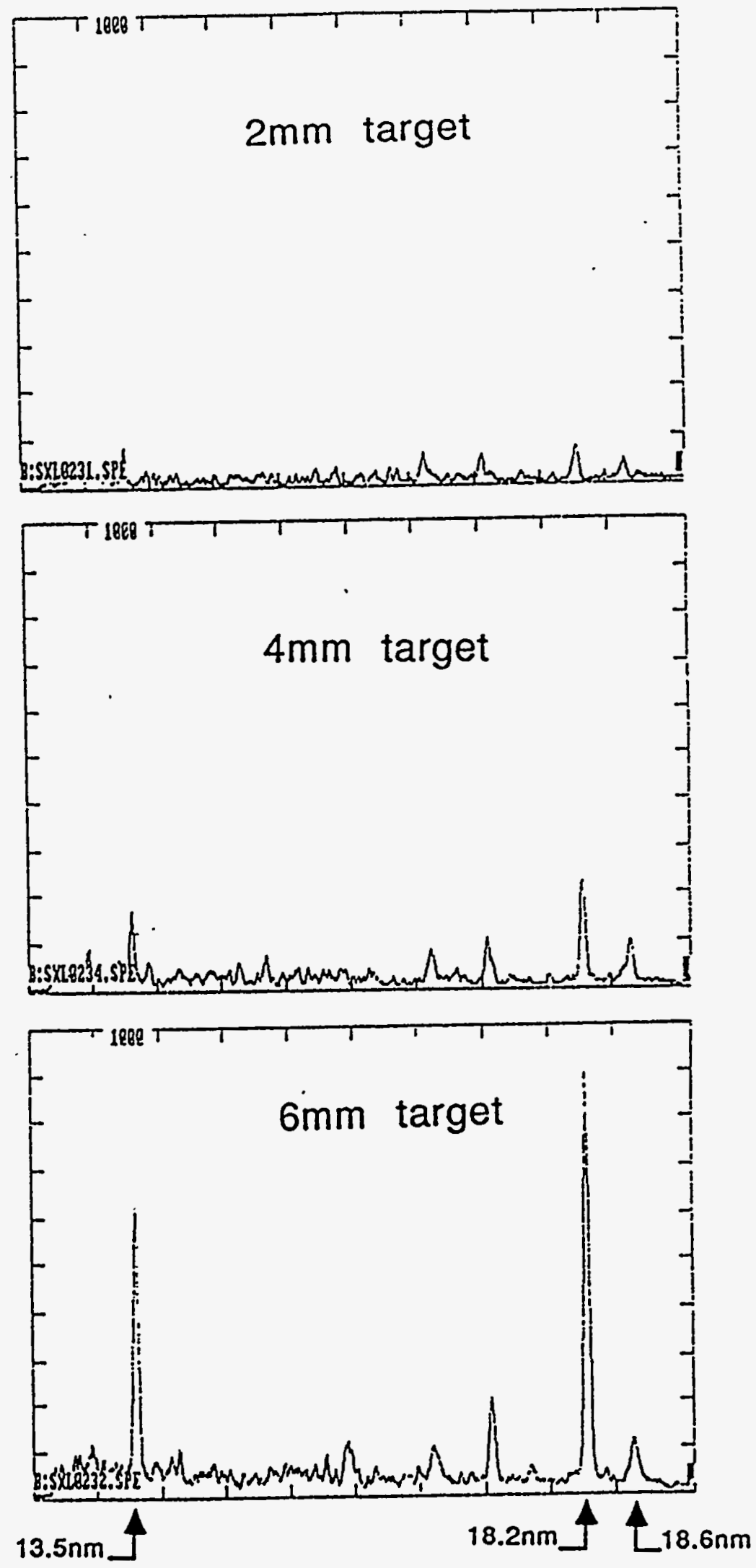

Fig. 3 
$1 \mathrm{~mm}$

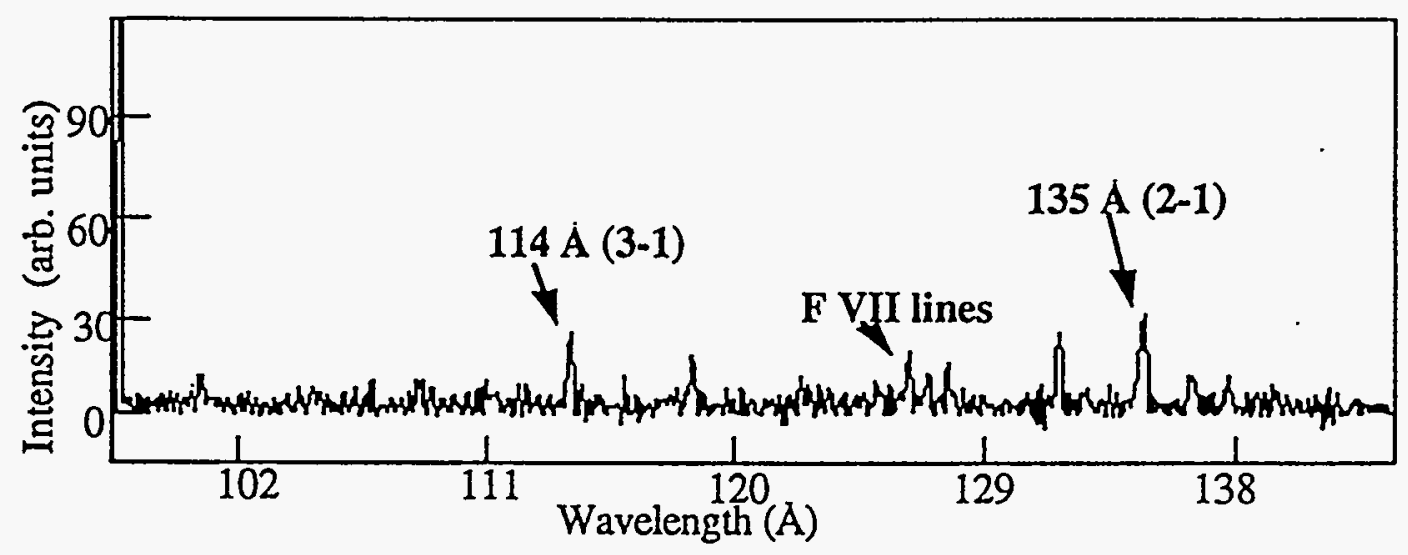

$2 \mathrm{~mm}$

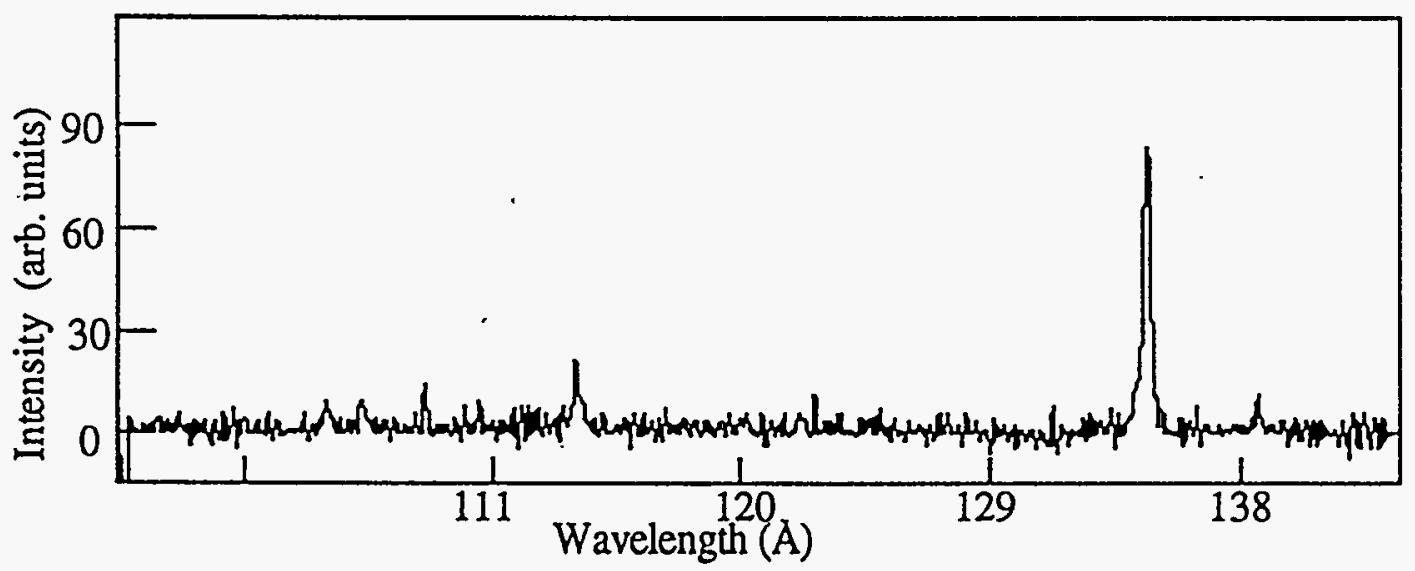

Fig. 4 

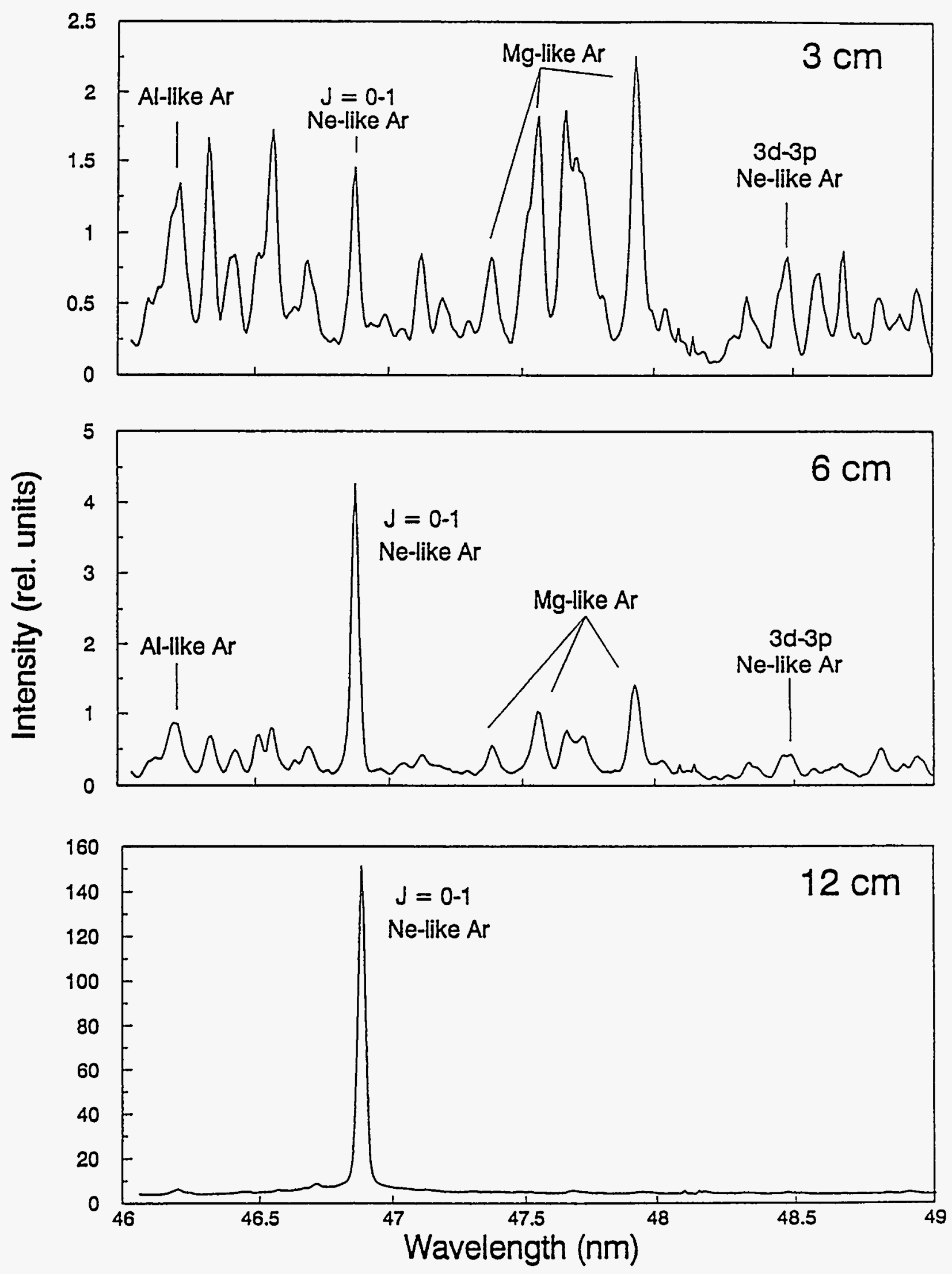

Fig. 5 


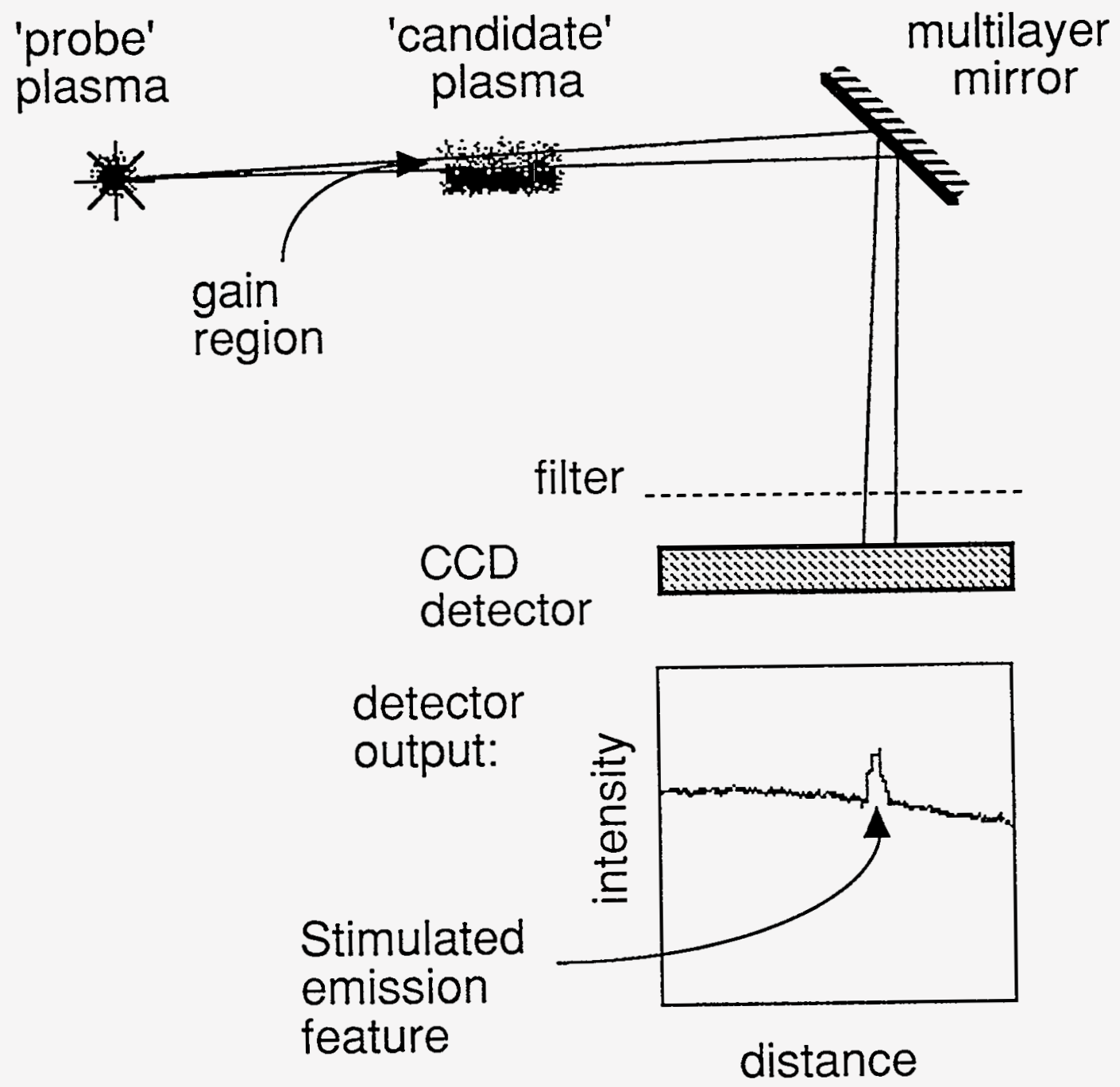

Fig. 6 
Dr. F. Paoloni, Univ. of Wollongong, AUSTRALIA

Prof. R.C. Cross, Univ. of Sydney, AUSTRALIA

Plasma Research Lab., Australian Nat. Univ., AUSTRALIA

Prof. I.R. Jones, Flinders Univ, AUSTRALIA

Prof. F. Cap, Inst. for Theoretical Physics, AUSTRIA

Prof. M. Heindler, Institut für Theoretische Physik, ALSTRIA

Prof. M. Goossens, Astronomisch Instituut, BELGIUM

Ecole Royale Militaire, Lab. de Phy. Plasmas, BELGIUM

Commission-European, DG. XII-Fusion Prog., BELGIUM

Prof. R. Bouciqué, Rijksuniversiteit Gent, BELGIUM

Dr. P.H. Sakanaka, Instituto Fisica, BRAZIL

Prof. Dr. I.C. Nascimento, Instituto Fisica, Sao Paulo, BRAZIL Instituto Nacional De Pesquisas Espaciais-INPE, BRAZIL

Documents Office, Atomic Energy of Canada Ltd., CANADA

Ms. M. Morin, CCFMTokamak de Varennes, CANADA

Dr. M.P. Bachynski, MPB Technologies, Inc., CANADA

Dr. H.M. Skarsgard, Univ. of Saskatchewan, CANADA

Prof. J. Teichmann, Univ. of Montreal, CANADA

Prof. S.R. Sreenivasan, Univ. of Calgary, CANADA

Prof. T.W. Johnston, INRS-Energie, CANADA

Dr. R. Bolton, Centre canadien de fusion magnétique, CANADA

Dr. C.R. James., Univ. of Alberta, CANADA

Dr. P. Lukác, Komenského Universzita, CZECHO-SLOVAKIA

The Librarian, Culham Laboratory, ENGLAND

Library, R61, Rutherford Appleton Laboratory, ENGLAND

Mrs. S.A. Hutchinson, JET Library, ENGLAND

Dr. S.C. Sharma, Univ. of South Pacific, FIJI ISLANDS

P. Mähönen, Univ. of Helsinki, FINLAND

Prof. M.N. Bussac, Ecole Polytechnique, FRANCE

C. Mouttet, Lab. de Physique des Milieux lonisés, FRANCE

J. Radet, CEN/CADARACHE - Bat 506, FRANCE

Prof. E. Economou, Univ. of Crete, GREECE

Ms. C. Ainni, Univ. of loannina, GREECE

Preprint Library, Hungarian Academy of Sci., HUNGARY

Dr. B. DasGupta, Saha Inst. of Nuclear Physics, INDIA

Dr. P. Kaw, Inst. for Plasma Research, INDIA

Dr. P. Rosenau, Israel Inst. of Technology, ISRAEL

Librarian, International Center for Theo Physics, ITALY

Miss C. De Palo, Associazione EURATOM-ENEA, ITALY

Dr. G. Grosso, Istituto di Fisica del Plasma, ITALY

Prof. G. Rostangni, Istituto Gas Ionizzati Del Cnr, ITALY
Dr. H. Yamato, Toshiba Res \& Devel Center, JAPAN

Prof. I. Kawakami, Hiroshima Univ., JAPAN

Prof. K. Nishikawa, Hiroshima Univ., JAPAN

Librarian, Naka Fusion Research Establishment, JAERI, JAPAN

Director, Japan Atomic Energy Research Inst., JAPAN

Prof. S. Itoh, Kyushu Univ., JAPAN

Research Info. Ctr., National Instit. for Fusion Science, JAPAN

Prof. S. Tanaka, Kyoto Univ., JAPAN

Library, Kyoto Univ., JAPAN

Prof. N. Inoue, Univ. of Tokyo, JAPAN

Secretary, Plasma Section, Electrotechnical Lab., JAPAN

Dr. O. Mitarai, Kumamoto Inst. of Technology, JAPAN

Dr. G.S. Lee, Korea Basic Sci. Ctr., KOREA

J. Hyeon-Sook, Korea Atomic Energy Research Inst., KOREA

D.I. Choi, The Korea Adv. Inst. of Sci. \& Tech., KOREA

Prof. B.S. Liley, Univ. of Waikato, NEW ZEALAND

Inst of Physics, Chinese Acad Sci PEOPLE'S REP. OF CHINA

Library, Inst. of Plasma Physics, PEOPLE'S REP. OF CHINA

Tsinghua Univ. Library, PEOPLE'S REPUBLIC OF CHINA

Z. Li, S.W. Inst Physics, PEOPLE'S REPUBLIC OF CHINA

Prof. J.A.C. Cabral, Instituto Superior Tecnico, PORTUGAL

Prof. M.A. Hellberg, Univ. of Natal, S. AFRICA

Prof. D.E. Kim, Pohang inst. of Sci. \& Tech., SO. KOREA

Prof. C.I.E.M.A.T, Fusion Division Library, SPAIN

Dr. L. Stenflo, Univ. of UMEA, SWEDEN

Library, Royal Inst. of Technology, SWEDEN

Prof. H. Wilhelmson, Chalmers Univ. of Tech., SWEDEN

Centre Phys. Des Plasmas, Ecole Polytech, SWITZERLAND

Bibliotheek, Inst. Voor Plasma-Fysica, THE NETHERLANDS

Asst. Prof. Dr. S. Cakir, Middle East Tech. Univ., TURKEY

Dr. V.A. Glukhikh,Sci. Res. Inst. Electrophys.l Apparatus, USSR

Dr. D.D. Ryutov, Siberian Branch of Academy of Sci., USSR

Dr. G.A. Eliseev, I.V. Kurchatov Inst., USSR

Librarian, The Ukr.SSR Academy of Sciences, USSR

Dr. L.M. Kovrizhnykh, Inst. of General Physics, USSR

Kemforschungsanlage GmbH, Zentralbibliothek, W. GERMANY

Bibliothek, Inst. Für Plasmaforschung, W. GERMANY

Prof. K. Schindler, Ruhr-Universitát Bochum, W. GERMANY

Dr. F. Wagner, (ASDEX), Max-Planck-Institut, W. GERMANY

Librarian, Max-Planck-Institut, W. GERMANY 